\title{
Evidence for Transient Perinatal Glutamatergic Innervation of Globus Pallidus
}

\author{
Timothy Greenamyre, ${ }^{1,2}$ John B. Penney, ${ }^{1,2}$ Anne B. Young, ${ }^{1,2}$ Christopher Hudson, ${ }^{3}$ Faye S. Silverstein, ${ }^{2,3}$ and \\ Michael V. Johnston ${ }^{1-4}$ \\ 'Neurosciences Program, Departments of ${ }^{2}$ Neurology and ${ }^{3 P}$ ediatrics, and ${ }^{4}$ Center for Human Growth and Development, \\ University of Michigan, Ann Arbor, Michigan 48104
}

\begin{abstract}
There is no known glutamatergic innervation of globus pallidus (GP) in adult mammals, but we report that during postnatal development of the GP there are large, transient increases in both presynaptic high-affinity glutamate uptake and postsynaptic $\mathrm{Na}^{+}$-independent glutamate receptor binding. These glutamatergic markers increase rapidly in rat GP after birth and then decrease to adult levels over a period of weeks. A similar developmental pattern of pallidal glutamate binding was found in human brains. In contrast, binding in rat caudate-putamen (CPu) increases after birth, reaches a peak, and remains constant into adulthood. The results suggest that a glutamatergic pathway transiently innervates the globus pallidus during the perinatal period. Because glutamate is an excitotoxin, this pathway may account, in part, for the basal ganglia damage seen in some forms of cerebral palsy after perinatal hypoxia/ischemia.
\end{abstract}

Although there is convincing anatomical and physiological evidence for the reorganization of neuronal processes and synapses in the central nervous system during the early postnatal period (Cowan, 1973; Purves and Lichtman, 1980; Stanfield, 1984), little is known about the biochemical and pharmacological correlates of such phenomena. In particular, it is not known how specific neurotransmitter systems are involved in this developmental reorganization. It is likely that changes in the connectivity and regional distribution of various transmitter systems play a major role in the specific behaviors exhibited by animals at different maturational levels. It is also possible that developmental changes in neurochemical anatomy may determine the age-dependent selective vulnerability of regions of the CNS to various insults, such as hypoxia/ischemia (Meldrum, 1985).

Glutamate is the putative neurotransmitter of a variety of excitatory pathways in the CNS (Watkins and Evans, 1981; Fagg and Foster, 1983; Fonnum, 1984). In addition to its transmitter function, glutamate and some of its analogs have neurotoxic properties and can produce "excitotoxic" lesions reminiscent

Received Apr. 14, 1986; revised Sept. 12, 1986; accepted Sept. 15, 1986

We thank Zane Hollingsworth for expert technical assistance and Darrel Debowey for photographic work. This work was supported by United Cerebral Palsy Foundation Grants R-305-82 and R-326-82, National Science Foundation Grant BNS8118765, USPHS Grants NS 17642 and NS 19613, a Canadian Medical Research Council Postdoctoral Fellowship to F.S.S., and an NIMH Individual Predoctoral NRSA to T.G. (MH08922).

Correspondence should be addressed to Dr. Anne B. Young, University of Michigan, Neuroscience Laboratory Building, 1103 East Huron, Ann Arbor, MI 48104.

Copyright (C) 1987 Society for Neuroscience $0270-6474 / 87 / 041022-09 \$ 02.00 / 0$ of human neurodegenerative disorders (Olney et al., 1971; Fuxe et al., 1983; Olney, 1983). Abnormally enhanced glutamatergic neurotransmission may be involved in the pathogenesis of chronic neurodegenerative diseases, such as Huntington's disease (Coyle and Schwarcz, 1976; McGeer and McGeer, 1976) and olivopontoccrcbcllar atrophy (Plaitakis et al., 1982), as well as the more acute neuronal death associated with status epilepticus (Schwarcz and Meldrum, 1985; Sloviter and Dempster, 1985), hypoxia/ischemia (Simon et al., 1984; Meldrum, 1985), and hypoglycemia (Wieloch, 1985). Thus, developmental changes in glutamatergic innervation may not only be important in the normal maturation of the CNS, but may also play a role in the selective vulnerability of certain brain regions to excitotoxic events. We have examined the development of both pre- and postsynaptic indices of the excitotoxic transmitter glutamate in the basal ganglia of rat and human brains. Some of this work has been published in abstract form (Greenamyre et al., 1984a).

\section{Materials and Methods}

Tissue. Sprague-Dawley rats at various ages between postnatal day 1 (PND 1) and adulthood were decapitated and their brains were quickly removed, mounted on cryostat chucks with Lipshaw embedding matrix, and frozen under powdered dry ice. The mounted brains were equilibrated to $-20^{\circ} \mathrm{C}$, and $20 \mu \mathrm{m}$ coronal sections were cut and thaw-mounted onto gelatin-coated ("subbed") slides. Fifty micrometer coronal sections from 6 neurologically normal human adult brains (mean age \pm SEM $=56 \pm 7$; range, 22-74) and 2 human infant brains ( 2 and 6 weeks of age) were also cut and mounted onto subbed slides. Mounted sections of rat brain were assayed for glutamate binding within $4 \mathrm{hr}$ of cutting and sections of human brain were assayed within $24 \mathrm{hr}$. Prior to assay, tissue was incubated for $30 \mathrm{~min}$ in a large volume of ice-cold $50 \mathrm{~mm}$ Tris- $\mathrm{HCl}$ containing $2.5 \mathrm{~mm} \mathrm{CaCl}$ or $50 \mathrm{~mm}$ Tris-acetate without calcium $\left(\mathrm{pH} 7.2\right.$ at $\left.2^{\circ} \mathrm{C}\right)$ in order to remove endogenous competitors. Previous studies have shown that glutamate that is bound to receptors dissociates with a $T_{1 / 2}$ of 0.4 min (Greenamyre et al., 1983). After this incubation, the slides were dried under a stream of cool air. The buffer used in this "prewash" (Tris-HCl with $\mathrm{CaCl}_{2}$ or Tris-acetate) was always the same as that used in subsequent binding assays and rinses, as described below.

Receptor autoradiography. A detailed description of the glutamatebinding assay has been published (Greenamyre et al., 1984b, 1985a, b) Briefly, in glutamate saturation studies, tissue sections were incubated with $30 \mathrm{nM} \mathrm{L}^{-3} \mathrm{H}$-glutamate (Amersham, Arlington Heights, IL; sp act, $30-45 \mathrm{Ci} / \mathrm{mmol}$ ) and varying concentrations of unlabeled glutamate, ranging from $1 \mathrm{nM}$ to $10 \mu \mathrm{M}$ in $50 \mathrm{~mm}$ Tris- $\mathrm{HCl}$ containing $2.5 \mathrm{~mm}$ $\mathrm{CaCl}_{2}$ or Tris-acetate (pH 7.2) for $45 \mathrm{~min}$ at $2^{\circ} \mathrm{C}$. Some sections of rat brain were incubated with $60 \mathrm{nM}{ }^{14} \mathrm{C}$-glutamate (Amersham; sp act, 50 $\mathrm{mCi} / \mathrm{mmol}$ ) instead of ${ }^{3} \mathrm{H}$-glutamate. Nonspecific binding was determined in adjacent sections in the presence of $1 \mathrm{~mm}$ unlabeled glutamate, and represented less than $10 \%$ of total binding. Similar "blanks" were obtained with $1 \mathrm{~mm}$ quisqualate (Sigma, St. Louis, MO). Detailed competition studies were performed in the presence of $200 \mathrm{nM} \mathrm{L}^{-}{ }^{3} \mathrm{H}$-gluta- 


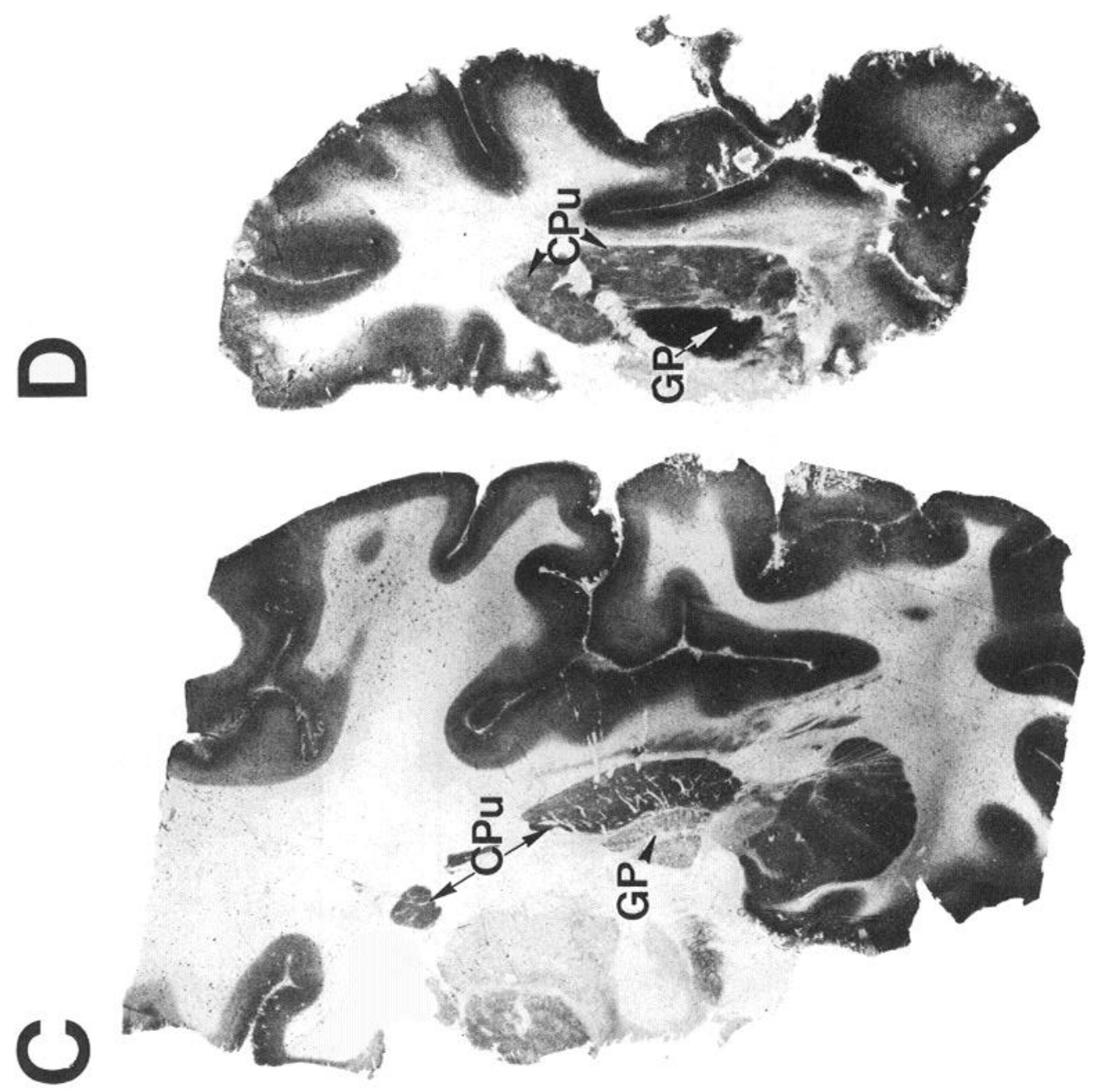

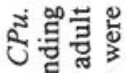

ช.

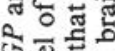

의의

空量

ठํ

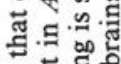

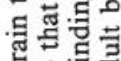

응휴 궁

촌

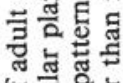

ㅎํ를

동

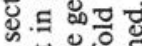

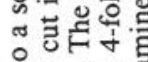

on.

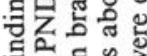

둥 政

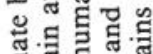

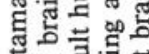

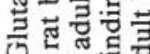

0 능

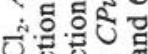

Uึ

¿

n.

on. 들.

管

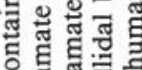

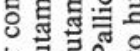

急寻寻串

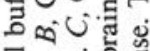

प्रिं

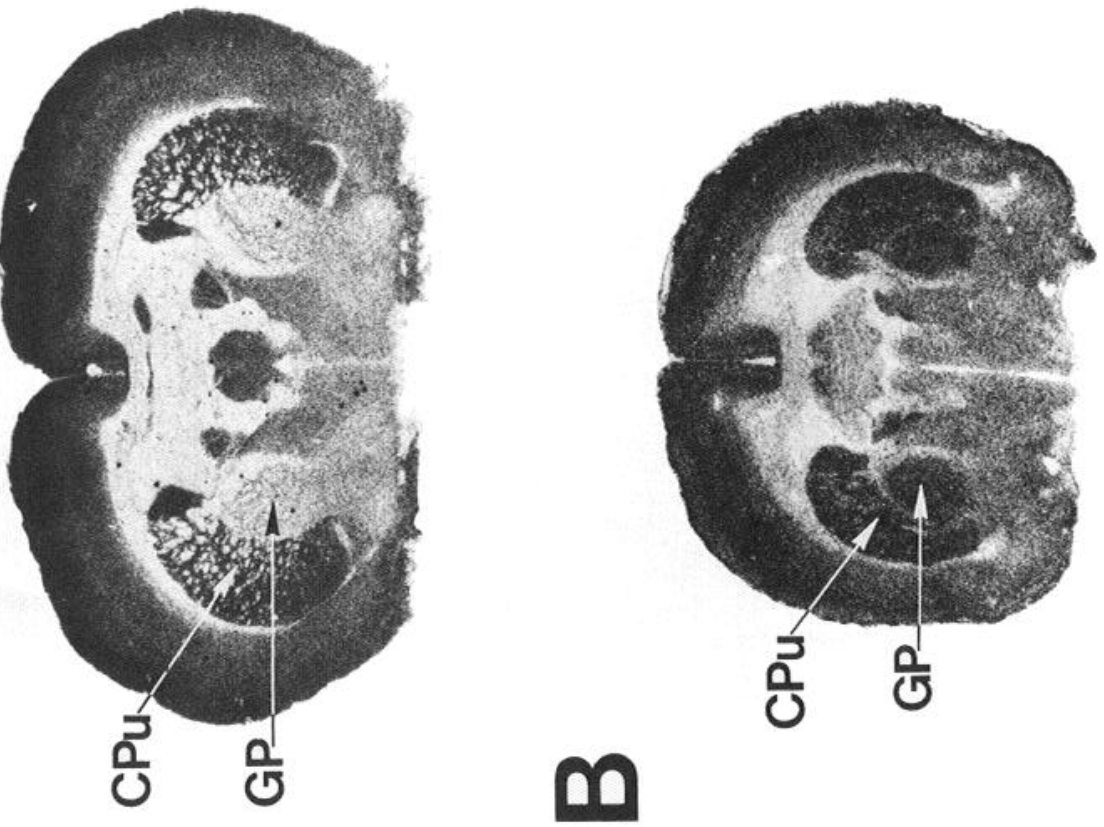

记鬲

도을

피 중

을 을

흥ㄷㅀ음

吨

है.

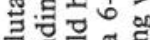

कํㅡㅁㅎㅇㅇ.

प्रित

능 종웡

등형

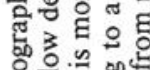

정해

읍 ․ㅗㅂ

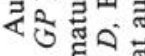

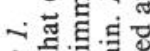

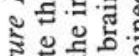

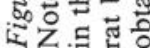


mate (sp act, $4.5 \mathrm{Ci} / \mathrm{mmol}$ ) using quisqualate concentrations ranging from $1 \mathrm{nM}$ to $1 \mathrm{~mm}$. The human coronal sections were incubated with $200 \mathrm{nM} \mathrm{L}^{3}{ }^{3} \mathrm{H}$-glutamate (sp act, $4.5 \mathrm{Ci} / \mathrm{mmol}$ ) in the presence or absence of $1 \mathrm{~mm}$ unlabeled glutamate.

After the incubation, sections were rinsed 3 times with ice-cold buffertwice with cold $2.5 \%$ glutaraldehyde in acetone in order to dry the slides rapidly and minimize uneven dissociation during drying - and then were blown dry under a stream of warm air. The elapsed time from the removal of the slides from the incubation medium until the tissue was dry was approximately $10 \mathrm{sec}$.

Human and rat tissue sections were also assayed for muscarinic cholinergic receptors, using ${ }^{3} \mathrm{H}$-quinuclidinyl benzilate (QNB); benzodiazepine receptors, using ${ }^{3} \mathrm{H}$-flunitrazepam; and $\mathrm{GABA}_{\mathrm{A}}$ receptors, using ${ }^{3} \mathrm{H}$-muscimol, as described previously (Penney and Young, 1982; Walker et al., 1984; Pan et al., 1985).

Analysis of autoradiograms. After the receptor assays, slides were placed in $\mathrm{x}$-ray cassettes with appropriate standards and exposed to Ultrofilm ${ }^{3} \mathrm{H}$ (LKB) for $10 \mathrm{~d}\left({ }^{3} \mathrm{H}\right.$-flunitrazepam and $\left.{ }^{3} \mathrm{H}-\mathrm{QNB}\right), 16 \mathrm{~d}\left({ }^{3} \mathrm{H}-\right.$ glutamate and ${ }^{14} \mathrm{C}$-glutamate in rat tissue), $21 \mathrm{~d}\left({ }^{3} \mathrm{H}\right.$-muscimol), or 60 d ( ${ }^{3} \mathrm{H}$-glutamate in human tissue). Following exposure, the film was developed in D-19, fixed, and dried. A spot-densitometer (Dauth et al., 1984) was used to measure radioactivity in areas of interest on the autoradiograms, as described previously (Pan et al., 1983). All binding data were obtained densitometrically from the autoradiograms. Quisqualate competition data were analyzed by an iterative curve-fitting program (Munson and Rodbard, 1980).

Glutamate uptake. Adult and PND 7 rats were decapitated and the brains quickly removed and placed in cold-buffered $0.32 \mathrm{M}$ sucrose ( $\mathrm{pH}$ 7.4). The brains were cut at $4^{\circ} \mathrm{C}$ into $1 \mathrm{~mm}$ slabs. One millimeter punches of tissue from globus pallidus (GP) and caudate-putamen (CPu) were ohtained from the slabs, and right and left punches from each area in the individual animals were pooled and placed in $1 \mathrm{ml}$ of cold-buffered $0.32 \mathrm{M}$ sucrose. Punch sites were confirmed histologically in postfixed, stained sections of the tissue slabs. The tissue was gently homogenized and uptake was assayed as described previously (Young et al., 1974). Under assay conditions, glutamate uptake was linear with tissue concentration and time, less than $10 \%$ of the substrate was accumulated, and uptake was predominantly into the synaptosomal fraction.

\section{Results}

\section{Autoradiography of glutamate binding}

In adult rats and humans there is a paucity of ${ }_{\mathrm{L}}{ }^{3} \mathrm{H}$-glutamate binding sites in GP, as compared with $\mathrm{CPu}$ (Fig. 1, $A, C$ ). Howcver, in the rat pup at PND 7, glutamate binding in GP is equal to binding in $\mathrm{CPu}$ and is 3-fold higher than adult levels when binding is assayed in Tris- $\mathrm{HCl}$ containing $2.5 \mathrm{mM} \mathrm{CaCl}_{2}$ (Figs. $1 B ; 2 ; 3, C, G)$. When glutamate binding was examined in the brains of 2 human infants ( 2 and 6 weeks of age), a similar phenomenon was discovered. GP binding exceeded $\mathrm{CPu}$ binding and was more than 4-fold higher than adult levels (Fig. $1 D$ ).

The developmental time course of glutamate binding in rat GP and CPu was studied from PND 1 to adulthood ( $>8$ weeks old). The level of binding in GP at PND 1 was equal to that in GP of adult rats, while CPu binding at PND 1 was only about $30 \%$ of adult levels (Figs. 2, 3). In addition, binding in GP was equal to binding in CPu at PND 1. Between PND 1 and 7, binding in both nuclei increased rapidly in parallel. After PND 7 , binding in $\mathrm{CPu}$ remained relatively constant at adult levels, but pallidal binding decreased over a period of weeks, reaching adult values after 4 weeks of age. Thus, pallidal glutamate binding transiently increased after birth and then decreased as the brain matured. Saturation analysis indicated that the decrease in pallidal binding during ontogenesis was the result of a decrease in the number of binding sites (Fig. 4). The mean number of binding sites in PND 28 and PND 7 GP was $4.0 \pm 0.1$ and $12.8 \pm 2.2 \mathrm{pmol} / \mathrm{mg}$ protein $(p<0.01$; unpaired $t$ test $)$, respectively. Affinities of adult and PND 7 binding sites were $286 \pm 11$ and $228 \pm 58 \mathrm{nM}$, respectively. The pattern of binding

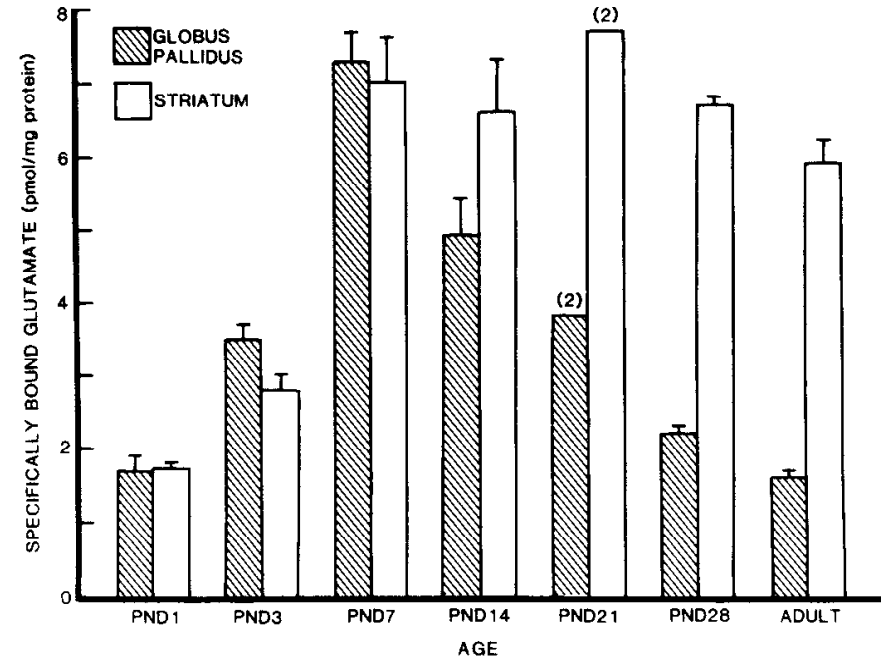

Figure 2. L- ${ }^{3} \mathrm{H}-$ Glutamate binding in globus pallidus $(G P)$ and striatum $(C P U)$ in the developing rat brain. The concentration of ${ }^{3} \mathrm{H}$-glutamate was $280 \mathrm{nM}$, close to the $K_{\mathrm{d}}$ of glutamate binding; the buffer was Tris$\mathrm{HCl}$, with $2.5 \mathrm{mM} \mathrm{CaCl}_{2}$. Values represent specific binding $\pm \mathrm{SEM}$ ( $n=3$ in all cases except at $P N D 21$, where $n=2$ ). Binding in $G P$ and $C P u$ increases rapidly from $P N D 1$ to $P N D 7$. After $P N D 7$, binding in $C P u$ (striatum) remains relatively constant but pallidal binding $(G P)$ decreases to adult levels over a period of weeks. Glutamate binding in $G P$ was significantly different from that in $C P u$ at $P N D 21(p<0.01)$, $P N D 28(p<0.01)$, and in adult rats $(p<0.05)$ by analysis of variance, using the Bonferroni inequality. In $G P$, binding at $P N D 3(p<0.01)$, $P N D 7(p<0.01)$, and $P N D 14(p<0.01)$ was significantly different from adult binding; in $C P u$, binding at $P N D 1(p<0.01)$ and $P N D 3$ $(p<0.01)$ was significantly different from adult binding, using Dunnett's $t$ test.

of ${ }^{14} \mathrm{C}$-glutamate in GP and $\mathrm{CPu}$ of adult rats was similar to that of tritiated glutamate (Fig. 5).

The heavy glutamate binding seen in GP when assayed in Tris- $\mathrm{HCl}$ containing $2.5 \mathrm{~mm} \mathrm{CaCl}_{2}$ was not present when binding was assayed in Tris-acetate (Fig. 6). Thus, this pallidal binding site appears to be chloride- and/or calcium-dependent. $N$-Methyl-D-aspartate (NMDA) and 2-amino-7-phosphonoheptanoic acid (AP7), an NMDA antagonist, did not compete for this site. Kainate and dihydrokainate, an uptake blocker, were also ineffective (data not shown). In contrast, quisqualate was able to compete for these pallidal binding sites in a biphasic manner (Fig. 7). The high-affinity component had a $K_{\mathrm{i}}$ of $58 \perp$ $50 \mathrm{nM}$ and the low-affinity component had a $K_{\mathrm{i}}$ of $36 \pm 7 \mu \mathrm{M}$ $(n=3)$. An average of $47 \%$ of the PND 7 pallidal glutamate binding sites was of the high-affinity QA type.

\section{Autoradiography of other ligands}

Muscarinic cholinergic binding in PND 7 GP and CPu was qualitatively similar to that in adult rats. There was very little binding in GP, compared to CPu (autoradiograms not shown). In addition, the binding of ${ }^{3} \mathrm{H}-\mathrm{QNB},{ }^{3} \mathrm{H}$-flunitrazepam, and ${ }^{3} \mathrm{H}$-muscimol to human infant basal ganglia was qualitatively similar to that in adults (Fig. 8).

\section{Glutamate uptake}

In adult rats there is much more uptake of glutamate in $\mathrm{CPu}$ than in GP $(189.3 \pm 17.3 \mathrm{pmol}$ glutamate $/ \mathrm{mg}$ protein $/ 5 \mathrm{~min}$ and $46.2 \pm 12.2 \mathrm{pmol}$ glutamatc/ $\mathrm{mg}$ protcin $/ 5 \mathrm{~min}$, respectively; $p<0.01$ by unpaired $t$ test). At PND 7, however, uptake 

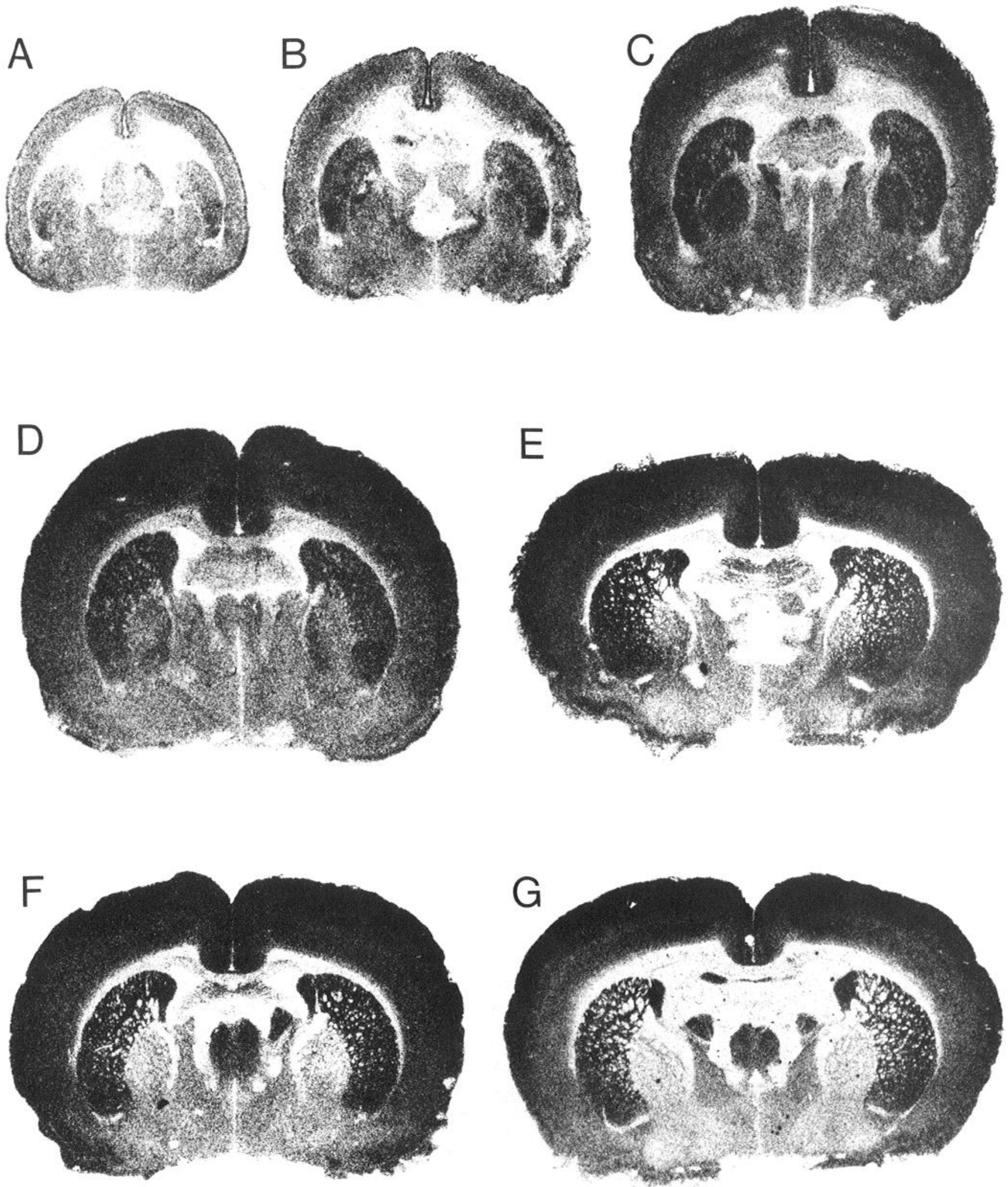

Figure 3. Autoradiographs of $\mathrm{L}^{-3} \mathrm{H}$-glutamate binding to rat brains of various ages. $A$, PND $1 ; B$, PND $3 ; C$, PND $7 ; D$, PND $14 ; E$, PND $21 ; F$, PND 28; $G$, adult. These autoradiographs were among those used to quantify the developmental changes in pallidal and striatal glutamate binding (Fig. 2). The buffer was Tris- $\mathrm{HCl}$ with $2.5 \mathrm{mM} \mathrm{CaCl}_{2}$. 


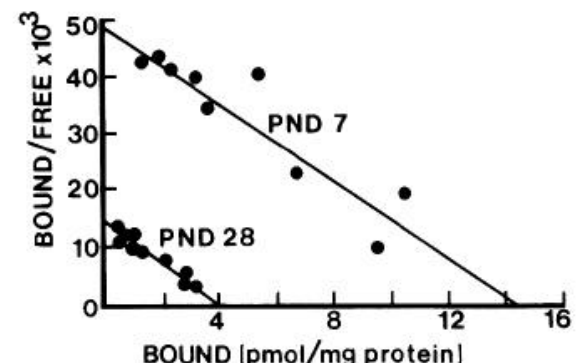

Figure 4. Representative Scatchard plots of glutamate binding to globus pallidus in $P N D 7$ and $P N D 28$ rats. The experiments were performed in Tris- $\mathrm{HCl}$ containing $2.5 \mathrm{mM} \mathrm{CaCl}_{2}$. Saturation studies indicate that the decrease in pallidal binding between $P N D 7$ and adulthood is the result of a decrease in the number of binding sites and is therefore not secondary to changes in pallidal glutamate levels (see Discussion). The experiment has been replicated in $3 P N D 7$ and $3 P N D 28$ rats with similar results, as described in Results.

in GP was not significantly different from that in $\mathrm{CPu}$, but was 2.4-fold higher than adult values, as shown in Figure 9.

\section{Discussion}

Anatomical and physiological studies have provided compelling evidence for the reorganization of neuronal processes and synapses during postnatal development of the CNS (Cowan, 1973; Purves and Lichtman, 1980). For example, it has been shown that the axons of cortical projection neurons initially send out multiple collaterals, many of which are subsequently eliminated during development (Stanfield, 1984). Glutamate is the putative neurotransmitter of a variety of corticofugal pathways, including the corticostriate pathway to CPu (Spencer, 1976; Divac et al., 1977; McGeer et al., 1977; Reubi and Cuenod, 1979; Young et al., 1983). No cerebral cortical projections to the GP of adult mammals have been described and the adult GP does not receive any known glutamatergic input. The involvement of cortical projection neurons in developmental CNS reorganization, together with the association between glutamate and cortical projections, raises the possibility that the glutamatergic system

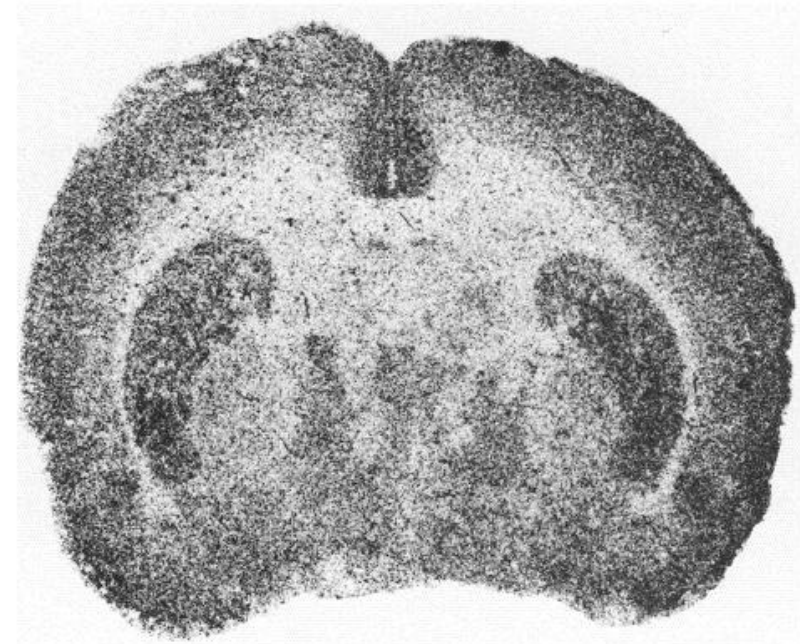

Figure 6. Autoradiograph of $\mathrm{L}^{-3} \mathrm{H}$-glutamate binding to a PND 7 rat brain assayed in $50 \mathrm{~mm}$ Tris-acetate buffer. Note that the heavy pallidal glutamate binding seen in $50 \mathrm{~mm}$ Tris- $\mathrm{HCl}$ containing $2.5 \mathrm{~mm}$ calcium ion (Figs. 1, 3) is not present when binding is assayed in this buffer. Thus, the pallidal binding site appears to be chloride- and/or calciumdependent (see text).

might be similarly involved in such reorganization.

In this study, we have examined the development of both pre- and postsynaptic indices of the excitotoxic transmitter glutamate in the basal ganglia of rat and human brains. As a measure of postsynaptic glutamatergic function, $\mathrm{Na}^{+}$-independent glutamate receptor binding was studied autoradiographically, as described previously (Greenamyre et al., 1984b, 1985a, b). Earlier studies from this laboratory and others have demonstrated an excellent correspondence between the distribution of postsynaptic glutamate binding sites and the projection areas of putative glutamatergic pathways (Greenamyre et al., 1984b; Halpain et al., 1984; Monaghan and Cotman, 1985). Lesion
Figure 5. Autoradiograph of $\mathrm{L}^{-14} \mathrm{C}$ glutamate binding to an adult rat brain in Tris- $\mathrm{HCl}$ buffer with $2.5 \mathrm{~mm} \mathrm{CaCl}$. Note that binding is much heavier in $C P u$ than in $G P$, similar to Figure $1 A$. This autoradiograph indicates that in adult rats there are, in fact, fewer glutamate receptors in $G P$ than in $C P u$ (see text). Therefore, the decrease in pallidal binding observed with ${ }^{3} \mathrm{H}$-glutamate from PND 7 to adulthood is not an artifact of myelination.

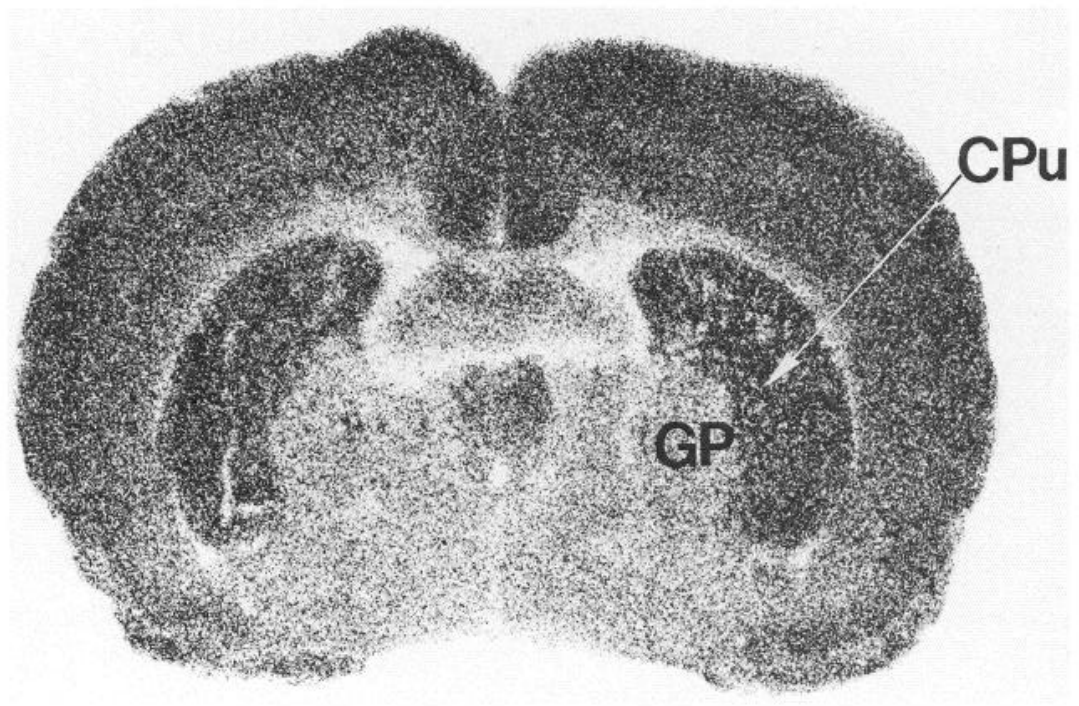




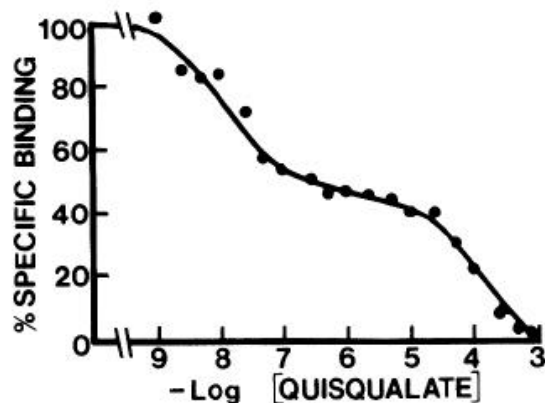

Figure 7. Representative curve showing quisqualate competition for glutamate binding sites in PND 7 GP assayed in Tris- $\mathrm{HCl}$ buffer containing $2.5 \mathrm{mM} \mathrm{CaCl}_{2}$. Data were analyzed with the LIGAND program (Munson and Rodbard, 1980), as described in Results. $\mathrm{L}^{-}{ }^{-\mathrm{H}}$-Glutamate concentration was $200 \mathrm{nM}$. Each point represents specific binding as defined in Materials and Methods. studies have also suggested that the $\mathrm{Na}^{+}$-independent glutamate binding sites are postsynaptic, since binding decreases dramatically in the $\mathrm{CPu}$ (but not the GP) of Huntington's disease brains (Greenamyre et al., 1985b), in the striatum (but not the GP) of rats with striatal kainate lesions (unpublished results), and in the cerebellar molecular layer of Purkinje cell-deficient mice (Olson et al., 1985). The autoradiographic technique is of particular value in this study because binding in GP can easily be distinguished from that in $\mathrm{CPu}$, even in immature rat pups. Thus, there are none of the problems with cross-contamination of tissue samples that can be encountered with microdissection techniques.

In previous studies, we have shown that glutamate binds to multiple receptor classes with very similar affinities, and that saturation isotherms of glutamate binding yield linear Scatchard plots and Hill coefficients of 1 (Greenamyre et al., 1984b, 1985a).

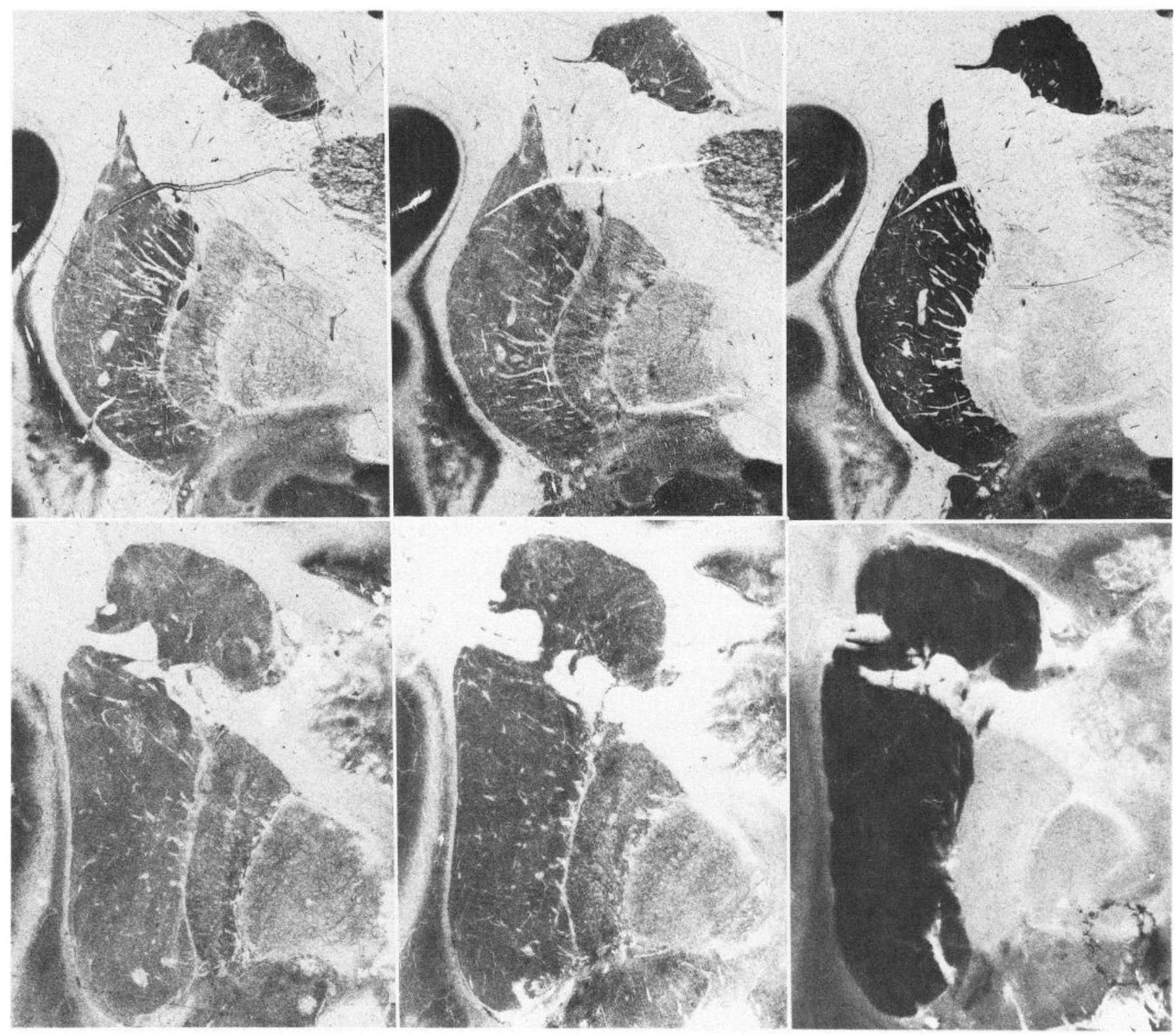

Figure 8. Autoradiographs of ${ }^{3} \mathrm{H}$-muscimol binding (left column), ${ }^{3} \mathrm{H}$-flunitrazepam binding (center column), and ${ }^{3} \mathrm{H}-\mathrm{QNB}$ binding (right column) in a human adult brain (top row) and an infant brain (bottom row). Note that the pattern of binding for each ligand is qualitatively similar in the adult and infant brains. 
Quisqualate displaces all specific glutamate binding biphasically with $K_{1} \mathrm{~s}$ for the high- and low-affinity sites that differ 1000 -fold (Greenamyre et al., 1984b, 1985a). The sites with a low affinity for quisqualate appear to be equivalent to the NMDA-sensitive sites. The high-affinity quisqualate binding site is markedly enhanced in the presence of calcium and chloride ions, whereas the low-affinity quisqualate sites (or NMDA sites) are unaffected by these ions (Greenamyre et al., 1985a). Therefore, binding to the high-affinity quisqualate site is markedly reduced when assayed in Tris-acetate buffer. The calcium- and chloride-enhanced quisqualate-sensitive binding site measured by our assay was not the calcium- and chloride-enhanced, 2-amino-4-phosphonobutyrate (AP4)-sensitive site described in fresh membranes (Fagg et al., 1982; Mena et al., 1982; Werling et al., 1983). This latter site is destroyed by freezing (Fagg et al., 1983b; Werling et al., 1983) and is not present in cryotome sections of brain. We and others have shown that AP4 has no effect on glutamate binding in frozen tissue sections (Monaghan et al., 1983; Greenamyre et al., 1985a).

In adult rats and humans, there is a paucity of glutamate binding sites in GP relative to CPu (Greenamyre et al., 1984b; Halpain et al., 1984; Monaghan and Cotman, 1985) and there is no known cortical or glutamatergic innervation of GP. However, we have shown here that glutamate binding in rat GP and $\mathrm{CPu}$ increased rapidly, in parallel, during the first postnatal week. Thcreafter, binding in $\mathrm{CPu}$ remained relatively constant at adult levels, but pallidal binding decreased over a period of weeks to its low adult level. Similarly, in human infant GP, glutamate binding was 4 -fold higher than that in adult brains.

If glutamate levels in immature GP were lower than in adult GP, it might be argued that there would be less endogenous glutamate to compete with radiolabeled glutamate at receptor sites early during development. Therefore, a selective, developmental increase in pallidal glutamate levels could cause artifically high glutamate binding in GP during the perinatal period. This possibility appears unlikely because glutamate binding in GP of PND 7 pups was not elevated when the binding was assayed in Tris-acetate. Furthermore, although a change in endogenous glutamate levels might cause an apparent change in binding site affinity, it would not change the number of binding sites. Saturation studies indicated that the decrease in pallidal binding during ontogenesis was due to a decrease in $B_{\max }$ and therefore could not be the result of changes in free glutamate levels.

The low-energy beta particles emitted by tritium are attenuated more by white matter than by gray matter (Rainbow et al., 1984; Kuhar and Unnerstall, 1985). Thus, it might be argued that the increase in pallidal binding in immature rats and humans is simply a reflection of a lack of myelin. If this were the case, it would be expected that the binding of other ligands would also be increased artifactually early in postnatal development. We have shown, however, that the binding of tritiated QNB, flunitrazepam, and muscimol to human infant GP and CPu was similar to that in adults. We have also examined this issue more directly. In order to investigate whether the decrease in binding after PND 7 was due to increased attenuation of beta particles caused by development of myelin, the binding of ${ }^{14} \mathrm{C}$-glutamate was examined in adult rats. The beta particles emitted by ${ }^{14} \mathrm{C}$ had greater energy than those emitted by tritium and thus there was very little attenuation by white matter when ${ }^{14} \mathrm{C}$ was used for autoradiography (Kuhar and Unnerstall, 1985). If the decreased pallidal binding after PND 7 were simply an artifact of

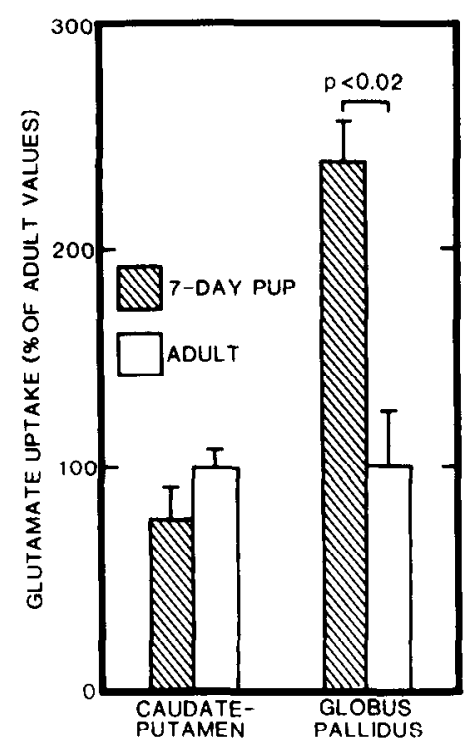

Figure 9. High-affinity synaptosomal glutamate uptake in $G P$ and $C P u$ in $P N D 7$ and adult rats. Uptake studies were performed with homogenized tissue punches from $3 P N D 7$ and 3 adult rat brains, as described previously (Young et al., 1974). Uptake was measured simultaneously in tissue from pups and adults. Results are expressed as percentages of adult values. The absolute values of glutamate uptake in adult GP and $C P u$ were $46.2 \pm 12.2$ and $189.3 \pm 17.3 \mathrm{pmol}$ glutamate $/ \mathrm{mg}$ protein $/ 5$ min, respectively, and in $P N D 7 G P$ and $C P u$ were $110.6 \pm 8.7$ and $144.4 \pm 28.7 \mathrm{pmol}$ glutamate $/ \mathrm{mg}$ protein $/ 5 \mathrm{~min}$, respectively. Statistical analysis was by 2 -tailed, unpaired $t$ test.

beta particle attenuation due to myelination, it would be expected that an autoradiograph of ${ }^{14} \mathrm{C}$-glutamate binding to adult brain would be similar to an autoradiograph of ${ }^{3} \mathrm{H}$-glutamate binding to a PND 7 brain. On the contrary, the image produced by glutamate labeled with ${ }^{14} \mathrm{C}$ was similar to the adult pattern produced by tritiated glutamate. Thus, the transient increase and subsequent decrease in binding cannot be accounted for by the development of myelin.

The pallidal glutamate binding site that increases in early postnatal development is dependent upon chloride and/or calcium ions and is not present when binding is assayed in Trisacetate. Chloride-dependent glutamate binding sites were first described by Mena et al. (1982). However, the site measured in this study was not the chloride-dependent, calcium-enhanced, AP4-sensitive glutamate binding site described in fresh homogenates (Fagg et al., 1982; Werling et al., 1983). Although quisqualate competition for the chloride-dependent, AP4-sensitive glutamate binding sites is typically biphasic (Fagg et al., 1983a; Nadler et al., 1985), the AP4-sensitive site is destroyed by freezing (Fagg et al., 1983b; Werling et al., 1983) and is not present in autoradiographic glutamate-binding assays (Monaghan et al., 1983; Greenamyre et al., 1985a). The pallidal binding site described here did not appear to correspond to the NMDA receptor (Davies et al., 1983) because neither NMDA nor AP7 competed for the binding of glutamate. Kainate was also inactive at this site, as was the uptake inhibitor dihydrokainate. In contrast, quisqualate was a potent competitor for about $50 \%$ of the pallidal glutamate binding sites and had a lower affinity for the remainder of the sites. The high-affinity quisqualate sites appeared to be similar to the neuronal chloride- and calciumdependent, quisqualate-sensitive receptors described on cerebellar Purkinje cells (Greenamyre et al., 1985a; Olson et al., 
1985). Previous work has indicated that in adult brains, the glutamate binding sites that have a low affinity for quisqualate are NMDA receptors (Greenamyre et al., 1985a). This was not the case in the immature GP, since neither NMDA nor AP7 competed for this site. The pharmacology of the low-affinity sites is unknown; however, it is clear that they do not correspond to NMDA, kainate, or high-affinity quisqualate receptors. It is also unlikely that they represent uptake sites, since the assay was performed at $2^{\circ} \mathrm{C}$, in the absence of sodium ions, and the uptake inhibitor dihydrokainate did not inhibit binding. It is possible that these pallidal low-affinity quisqualate sites are novel glutamate receptors that are expressed transiently during the development of the GP. The pharmacological profile of these sites is under investigation.

To examine whether there was a concomitant presynaptic correlate to the unusual temporal pattern of binding observed in GP, high-affinity synaptosomal glutamate uptake was examined in adult and PND 7 rats. High-affinity uptake of glutamate into synaptosomal preparations is a commonly used index of the relative density of glutamatergic terminals (Young et al., 1974; Fonnum et al., 1980). We found that, in adult rats, glutamate uptake was much higher in $\mathrm{CPu}$ than in GP, as reported by Fonnum and coworkers (1981). This was consistent with the dense glutamatergic innervation of $\mathrm{CPu}$ (Spencer, 1976; Divac et al., 1977; McGeer et al., 1977; Reubi and Cuenod, 1979; Young et al., 1983) and the lack of such input to GP. In contrast, we found that, in PND 7 rat pups, uptake of glutamate was $240 \%$ of the adult level. Thus, at 1 week of age, both preand postsynaptic indices of glutamatergic function were markedly increased over adult levels in rat GP.

These results suggest that there is a previously undescribed transient, glutamatergic innervation of GP during postnatal development in both rats and humans. Dvergsten et al. (1986) recently demonstrated the presence of a transient population of dendritic spines during the perinatal period in the cat entopeduncular nucleus, homologous to the medial GP of primates. This may represent an anatomical correlate of the apparent glutamatergic innervation of GP described during the perinatal period. At present, the source of this innervation is unknown, but the elimination of collaterals of cortical projection neurons during development is a well-described phenomenon (Stanfield, 1984) and many corticofugal pathways are thought to be glutamatergic (Fonnum et al., 1981; Young et al., 1981, 1983; Fagg and Foster, 1983). Further studies are under way to determine the source of this glutamatergic input. The present study also suggests that the glutamatergic system may be involved in the synaptic reorganization that occurs in the CNS as part of early postnatal development. The factors that control the development and subsequent regression of this innervation have yet to be determined. However, the findings reported here may further the understanding of the functional organization of immature basal ganglia (Penney and Young, 1983, 1986). Perhaps the transient neonatal glutamatergic input to GP accounts, in part, for the striking differences between infant and mature motor behaviors.

A glutamatergic innervation of GP may also have implications for the vulnerability of the GP to perinatal hypoxia/ischemia. Glutamate and its analogs are excitotoxins which can produce neuronal lesions reminiscent of human diseases (Fuxe et al., 1983; Olney, 1983). Transient cerebral ischemia elicits a large increase in extracellular glutamate levels in vivo (Benveniste et al., 1984). In addition, hypoxia/ischemia depresses high-affinity glutamate uptake (Silverstein et al., 1985) and may therefore prolong the neurotoxic actions of glutamate upon its receptors. In adults, global ischemia often results in preferential damage of cerebral cortex and hippocampus (Brierley and Graham, 1984; Meldrum, 1985), areas rich in receptors for excitatory amino acids (Monaghan et al., 1983; Greenamyre et al., 1984b, 1985a; Halpain et al., 1984). Ischemic damage to adult hippocampal neurons can be blocked by a specific antagonist of the NMDA receptor (Simon et al., 1984) or by transection of glutamatergic afferents to the hippocampus (Wieloch, 1985), which suggests that this damage is mediated by an endogenous excitotoxin such as glutamate.

Perinatal hypoxia/ischemia frequently causes pathology in the GP (Courville, 1953; Johnston, 1983; Larroche, 1984) and often results in cerebral palsy (Volpe, 1981). The glutamate binding sites described in this report are sensitive to quisqualate, which has potent excitotoxic effects (Coyle, 1983). Furthermore, it has been shown that intracerebral injection of quisqualate into PND 7 rat pups causes extensive neuronal necrosis in the GP (Silverstein et al., 1986, and unpublished observations). Thus, it appears that the quisqualate-sensitive receptors described here are functional and can mediate excitotoxic cell death. The high density of glutamate receptors and glutamatergic terminals in GP during the perinatal period raises the possibility that glutamate neurotoxicity may be involved in the pathogenesis of cerebral palsy, a common outcome of perinatal hypoxia and ischemia.

\section{References}

Benveniste, H., J. Drejer, A. Schousboe, and N. H. Diemer (1984) Elevation of the extracellular concentrations of glutamate and aspartate in rat hippocampus during transient cerebral ischemia monitored by intracerebral microdialysis. J. Neurochem. 43: 1369-1374.

Brierley, J. B., and D. I. Graham (1984) Hypoxia and vascular disorders of the central nervous system. In Greenfield's Neuropathology, J. H. Adams, J. A. N. Corsellis, and L. W. Duchen, eds., pp. 125207, Wiley, New York.

Courville, C. B. (1953) Cerebral Anoxia, pp. 155-216, San Lucas Press, Los Angeles.

Cowan, W. M. (1973) Neuronal death as a regulative mechanism in the control of cell number in the nervous system. In Development and Aging in the Nervous System, M. Rockstein, ed., pp. 19-41, Academic, New York.

Coyle, J. T. (1983) Neurotoxic action of kainic acid. J. Neurochem. 4: $1-11$.

Coyle, J. T., and R. Schwarcz (1976) Lesion of striatal neurons with kainic acid provides a model for Huntington's chorea. Nature 263: 244-246.

Dauth, G. W., K. A. Frey, and S. Gilman (1984) A densitometer for quantitative autoradiography. J. Neurosci. Methods 9: 243-251.

Davies, J., R. H. Evans, A. W. Jones, K. N. Mewett, D. A. S. Smith, and J. C. Watkins (1983) Recent advances in the pharmacology of excitatory amino acids in the mammalian central nervous system. In Excitotoxins, K. Fuxe, P. Roberts, and R. Schwarcz, eds., pp. 43-54, Plenum, New York.

Divac, I., F. Fonnum, and J. Storm-Mathisen (1977) High affinity uptake of glutamate in terminals of corticostriatal axons. Nature 266 : 377-378.

Dvergsten, C. L., C. D. Hull, M. S. Levine, A. M. Adinolfi, and N. A. Buchwald (1986) Postnatal differentiation and growth of cat entopeduncular neurons. A transient spiny period associated with branch elongation. Brain Res. 24: 239-251.

Fagg, G. E., and A. C. Foster (1983) Amino acid neurotransmitters and their pathways in the mammalian central nervous system. Neuroscience 9: 701-719.

Fagg, G. E., A. C. Foster, E. E. Mena, and C. W. Cotman (1982) Chloride and calcium ions reveal a pharmacologically distinct population of L-glutamate binding sites in synaptic membranes: Corre- 
spondence between biochemical and electrophysiological data. J. Neurosci. 2: 958-965.

Fagg, G. E., A. C. Foster, E. E. Mena, and C. W. Cotman (1983a) Chloride and calcium ions separate $\mathrm{L}$-glutamate receptor populations in synaptic membranes. Eur. J. Pharmacol. 88: 105-110.

Fagg, G. E., E. E. Mena, D. T. Monaghan, and C. W. Cotman (1983b) Freezing eliminates a specific population of $\mathrm{L}$-glutamate receptors in synaptic membranes. Neurosci. Lett. 38: 157-162.

Fonnum, F. (1984) Glutamate: A neurotransmitter in mammalian brain. J. Neurochem. 42: 1-11.

Fonnum, F., A. Soreide, I. Kvale, J. Walker, and I. Walaas (1981) Glutamate in cortical fibers. Adv. Biochem. Psychopharmacol. 27: 29-41.

Fonnum, F., R. Lund-Karlsen, D. Malthe-Sorensen, S. Sterri, and I. Walaas (1980) High affinity transport systems and their role in transmitter action. In The Cell Surface and Neuronal Function, C. W. Cotman, G. Poste, and G. L. Nicholson, eds., pp. 455-504, Elsevier/North Holland Biomedical Press, Amsterdam.

Fuxe, K., P. Roberts, and R. Schwarcz, eds. (1983) Excitotoxins, Plenum, New York.

Greenamyre, J. T., A. B. Young, and J. B. Penney (1983) Quantitative autoradiography of $\mathrm{L}-\left[{ }^{3} \mathrm{H}\right]$ glutamate to rat brain. Neurosci. Lett. 37 : $155-160$.

Greenamyre, J. T., J. B. Penney, F. Silverstein, M. V. Johnston, and A. B. Young (1984a) A transient, dense, postnatal expression of glutamate binding sites in globus pallidus. Soc. Neurosci. Abstr. 10: 225.

Greenamyre, J. T., A. B. Young, and J. B. Penney (1984b) Quantitative autoradiographic distribution of $\mathrm{L}-\left[{ }^{3} \mathrm{H}\right]$ glutamate binding sites in rat central nervous system. J. Neurosci. 4: 2133-2144.

Greenamyre, J. T., J. M. M. Olson, J. B. Penney, and A. B. Young (1985a) Autoradiographic characterization of $N$-methyl-D-aspartate-, quisqualate-, and kainate-sensitive glutamate binding sites. J. Pharmacol. Exp. Ther. 233: 254-263.

Greenamyre, J. T., J. B. Penney, A. B. Young, C. J. D'Amato, S. P. Hicks, and I. Shoulson (1985b) Alterations in L- $\left[{ }^{3} \mathrm{H}\right]$ glutamate binding in Alzhcimcr's and Huntington's diseases. Science 227: 14691499.

Halpain, S. H., C. M. Wieczorek, and T. C. Rainbow (1984) Localization of $\mathrm{L}$-glutamate receptors in rat brain by quantitative autoradiography. J. Neurosci. 4: 2247-2258.

Johnston, M. V. (1983) Neurotransmitter alterations in a model of perinatal hypoxic-ischemic brain injury. Ann. Neurol. 13: 511-518.

Kuhar, M. J., and J. R. Unnerstall (1985) Quantitative receptor mapping by autoradiography: Some current technical problems. Trends Neurosci. $8: 49-53$.

Larroche, J.-C. (1984) Perinatal brain damage. In Greenfield's Neuropathology, J. H. Adams, J. A. N. Corsellis, and L. W. Duchen, eds., pp. 451-490, Wiley, New York.

McGeer, E. G., and P. L. McGeer (1976) Duplication of biochemical changes of Huntington's chorea by intrastriatal injections of glutamic and kainic acids. Nature 263: 517-519.

McGeer, P. L., E. G. McGeer, U. Scherer, and K. Singh (1977) A glutamatergic corticostriatal path? Brain Res. 128: 369-373.

Meldrum, B. (1985) Excitatory amino acids and anoxic/ischemic brain damage. Trends Neurosci. 8: 47-48.

Mena, E. E., G. E. Fagg, and C. W. Cotman (1982) Chloride ions enhance L-glutamate binding to rat brain synaptic membranes. Brain Res. 243: 378-381.

Monaghan, D. T., and C. W. Cotman (1985) Distribution of $N$-methylD-aspartate-sensitive $\mathbf{L}-\left[{ }^{3} \mathrm{H}\right]$ glutamate binding sites in rat brain. $\mathrm{J}$. Neurosci. 5: 2909-2919.

Monaghan, D. T., V. R. Holets, D. W. Toy, and C. W. Cotman (1983) Anatomical distributions of four pharmacologically distinct ${ }^{3} \mathrm{H}-\mathrm{L}-\mathrm{glu}-$ tamate binding sites. Nature 306: 176-179.

Munson, P. J., and D. Rodbard (1980) Ligand: A versatile computerized approach for characterization of ligand-binding systems. Anal. Biochem. 107: 220-239.

Nadler, J. V., A. Wang, and L. L. Werling (1985) Binding sites for $\mathrm{L}-\left[{ }^{3} \mathrm{H}\right]$ glutamate on hippocampal synaptic membranes: Three populations differentially affected by chloride and calcium ions. J. Neurochem. 44: 1791-1798.

Olney, J. W. (1983) Excitotoxins: An overview. In Excitotoxins, K. Fuxe, P. Roberts, and R. Schwarcz, eds., pp. 82-96, Plenum, New York.

Olney, J. W., O. L. Ho, and V. Rhee (1971) Cytotoxic effects of acidic and sulphur containing amino acids on the infant mouse central nervous system. Exp. Brain Res. 14: 61-76.

Olson, J. M. M., J. T. Greenamyre, J. B. Penney, and A. B. Young (1985) Autoradiographic localization of cerebellar glutamate receptor subtypes. Soc. Neurosci. Abstr. 11: 111.

Pan, H. S., K. A. Frey, A. B. Young, and J. B. Penney (1983) Changes in $\left[{ }^{3} \mathrm{H}\right]$ muscimol binding in substantia nigra, entopeduncular nucleus, globus pallidus and thalamus after striatal lesions as demonstrated by quantitative autoradiography. J. Neurosci. 3: 1189-1198.

Pan, H. S., J. B. Penney, and A. B. Young (1985) $\gamma$-Aminobutyric acid and benzodiazepine receptor changes induced by unilateral 6-hydroxydopamine lesions of the medial forebrain bundle. J. Neurochem. 45: 1396-1404.

Penney, J. B., and A. B. Young (1982) Quantitative autoradiography of neurotransmitter receptors in Huntington's disease. Neurology 32: 1391-1395.

Penney, J. B., and A. B. Young (1983) Speculations on the functional anatomy of basal ganglia disorders. Annu. Rev. Neurosci. 6: 73-94.

Penney, J. B., and A. B. Young (1986) Striatal inhomogeneities and basal ganglia function. Movement Disorders 1: 3-15.

Plaitakis, A., S. Berl, and M. Yahr (1982) Abnormal glutamate metabolism in an adult-onset degenerative neurological disorder. Science 216: 193-196.

Purves, D., and J. W. Lichtman (1980) Elimination of synapses in the developing nervous system. Science 210: 153-157.

Rainbow, T. C., A. Biegon, and D. J. Berck (1984) Quantitative receptor autoradiography with tritium-labeled ligands: Comparison of biochemical and densitometric measurements. J. Neurosci. Methods 11: 231-241.

Reubi, J. C., and M. Cuenod (1979) Glutamate release in vitro from corticostriatal terminals. Brain Res. 176: 185-188.

Schwarcz, R., and B. S. Meldrum (1985) Excitatory amino acid antagonists provide a therapeutic approach to neurological disorders. Lancet 2: 140-143.

Silverstein, F. S., K. Buchanon, and M. V. Johnston (1985) Hypoxiaischemia causes severe but reversible depression of striatal synaptosomal ${ }^{3} \mathrm{H}$-glutamate uptake. Ann. Ncurol. 18: 122 (abstract).

Silverstein, F. S., R. Chen, and M. V. Johnston (1986) The glutamate analogue quisqualic acid is neurotoxic in striatum and hippocampus of immature rat brain. Neurosci. Lett. $71: 13-18$.

Simon, R. R., J. H. Swan, T. Griffiths, and B. S. Meldrum (1984) Blockage of $N$-methyl-D-aspartate receptors may protect against ischemic damage in the brain. Science 226: 850-852.

Sloviter, R. S., and D. W. Dempster (1985) "Epileptic" brain damage is replicated qualitatively in the rat hippocampus by central injections of glutamate or aspartate but not by GABA or acetylcholine. Brain Res. Bull. 15: 39-60.

Spencer, H. J. (1976) Antagonism of cortical excitation of striatal neurons by glutamic acid diethyl ester: Evidence for glutamic acid as an excitatory transmitter in the rat striatum. Brain Res. 102:91-101.

Stanficld, B. B. (1984) Postnatal reorganization of cortical projections: The role of collateral elimination. Trends Neurosci. 7: 37-41.

Volpe, J. J. (1981) Neurology of the Newborn, pp. 180-238, W. B. Saunders, Philadelphia, PA.

Walker, F. O., A. B. Young, J. B. Penney, K. Dovorini-Zis, and I. Shoulson (1984) Benzodiazepine and GABA receptors in early Huntington's disease. Neurology 34: 1237-1240.

Watkins, J. C., and R. H. Evans (1981) Excitatory amino acid neurotransmitters. Annu. Rev. Pharmacol. Toxicol. 21: 165-204.

Werling, L. L., K. A. Doman, and J. V. Nadler (1983) L-[ $\left.{ }^{3} \mathrm{H}\right]$ glutamate binding to hippocampal synaptic membranes: Two binding sites discriminated by their differing affinities for quisqualate. J. Neurochem. 41: 586-593.

Wieloch, T. (1985) Endogenous excitotoxins as possible mediators of ischemic and hypoglycemic brain damage. Epilepsia 5: 501 .

Young, A. B., M. L. Oster-Granite, R. M. Herndon, and S. H. Snyder (1974) Glutamic acid: Selective depletion by viral-induced granule cell loss in hamster cerebellum. Brain Res. 73: 1-13.

Young, A. B., M. B. Bromberg, and J. B. Penney (1981) Decreased glutamate uptake in subcortical areas deafferented by sensorimotor cortical ablation in the cat. J. Neurosci. 1: 241-249.

Young, A. B., J. B. Penney, G. W. Dauth, M. B. Bromberg, and S. Gilman (1983) Glutamate or aspartate as a possible neurotransmitter of cerebral corticofugal fibers in the monkey. Neurology 33: 1513-1516. 